\title{
Dessins gnostiques de Daniel Dezeuze
}

Joëlle Pijaudier-Cabot

\section{(2) OpenEdition}

Journals

Édition électronique

URL : https://journals.openedition.org/rbnu/3254

DOI : $10.4000 /$ rbnu.3254

ISSN : 2679-6104

\section{Éditeur}

Bibliothèque nationale et universitaire de Strasbourg

\section{Édition imprimée}

Date de publication : 1 novembre 2011

Pagination : 96-107

ISSN : 2109-2761

\section{Référence électronique}

Joëlle Pijaudier-Cabot, «Dessins gnostiques de Daniel Dezeuze », La Revue de la BNU [En ligne], 4

2011, mis en ligne le 01 novembre 2011, consulté le 08 août 2021. URL : http://

journals.openedition.org/rbnu/3254 ; DOI : https://doi.org/10.4000/rbnu.3254

\section{(c) (1)(2) (2)}

La Revue de la BNU est mise à disposition selon les termes de la Licence Creative Commons Attribution - Pas d'Utilisation Commerciale - Partage dans les Mêmes Conditions 4.0 International. 


\section{Dessins gnostiques de Daniel Dezeuze}

Daniel Dezeuze est né à Alès en 1942. Membre fondateur en 1970 du groupe Supports-Surfaces, qui remit radicalement en question la pratique artistique traditionnelle, Daniel Dezeuze pose dans son œuvre la question du devenir de la peinture dans le paysage économique et culturel occidental. L'artiste procède par séries et par cycles : châssis, quadrillages de lattes de bois et assemblages, gazes découpées et dessins tantôt abstraits, tantôt figuratifs, sont autant de voies pour pousser le regard dans ses retranchements - un regard que l'œuvre vient troubler, inquiéter parfois et qu'elle invite à se situer dans une expérience spatiale étonnamment sensible. Les dix " dessins gnostiques " présentés ici (dimensions originales $32,5 \times 40 \mathrm{~cm}$.) ont été réalisés en 2008.

Joëlle Pijaudier-Cabot 


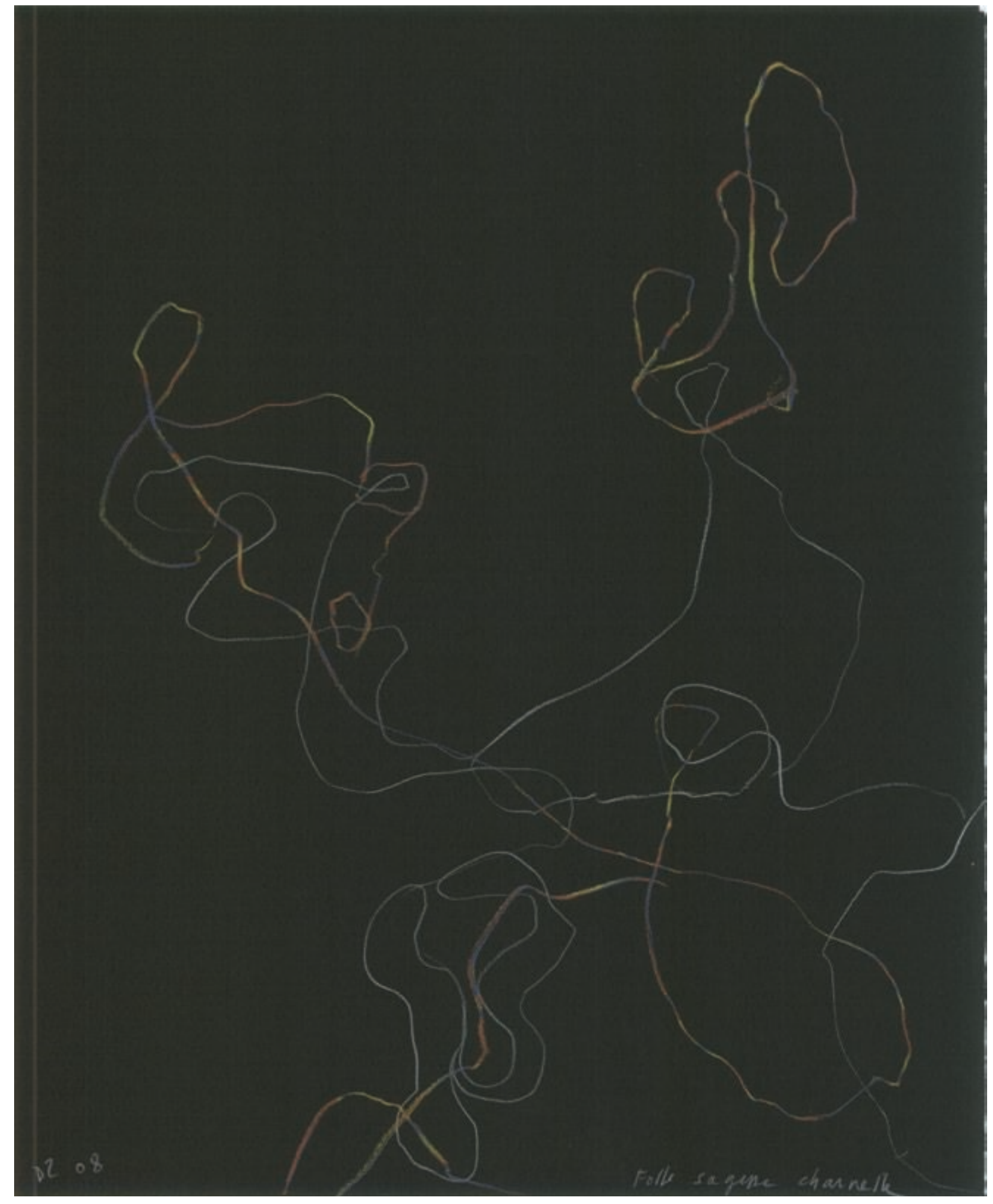




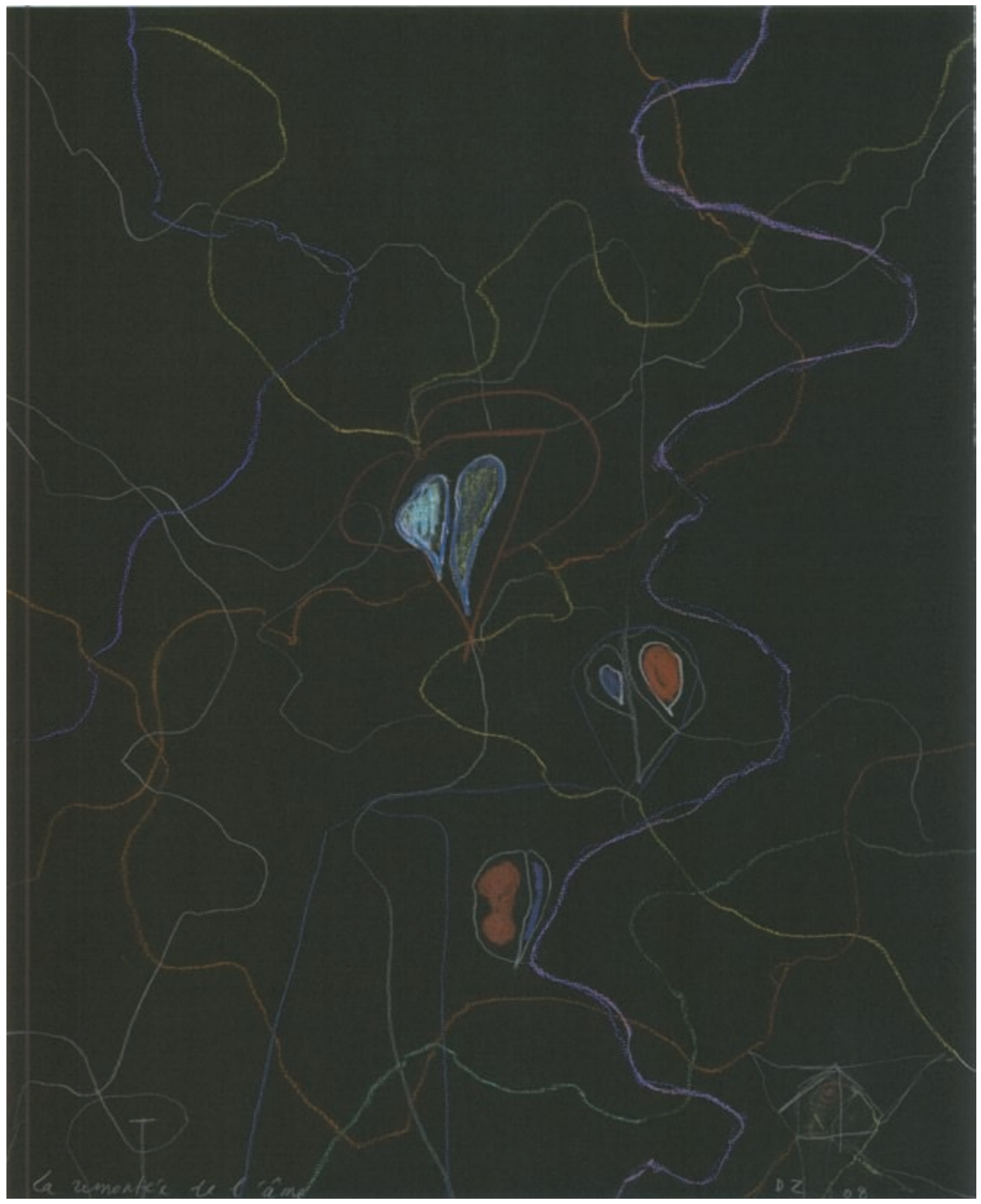




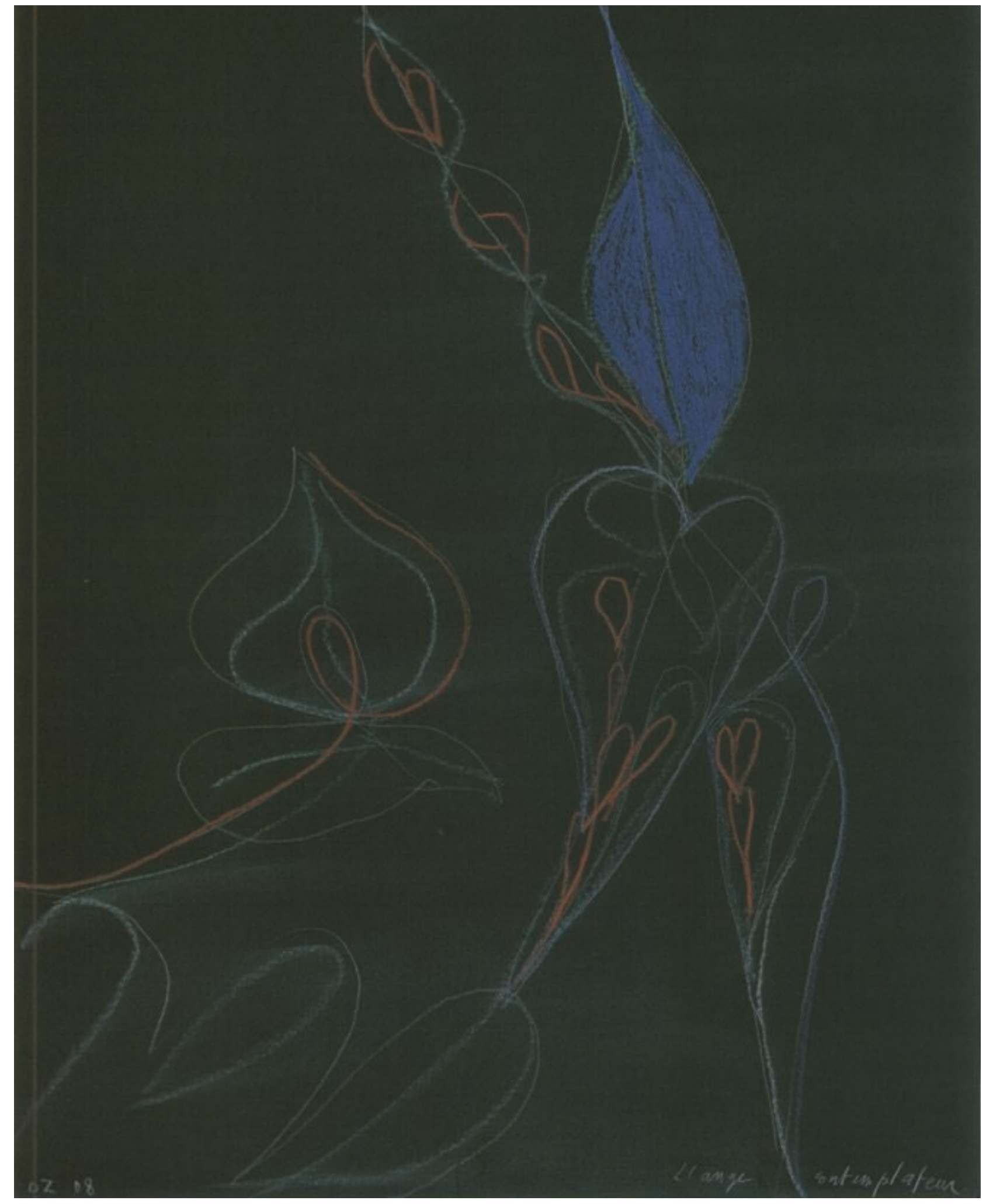




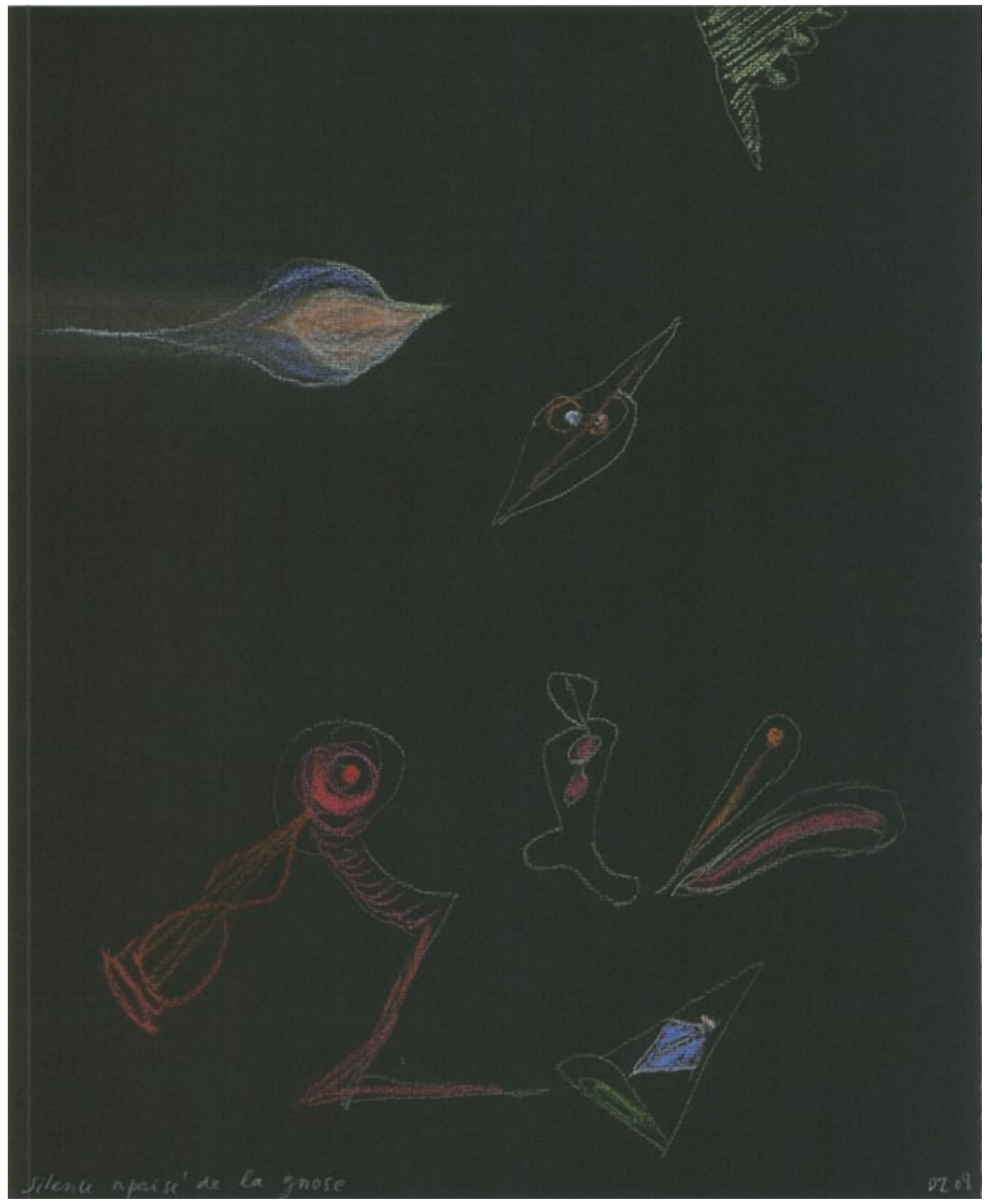




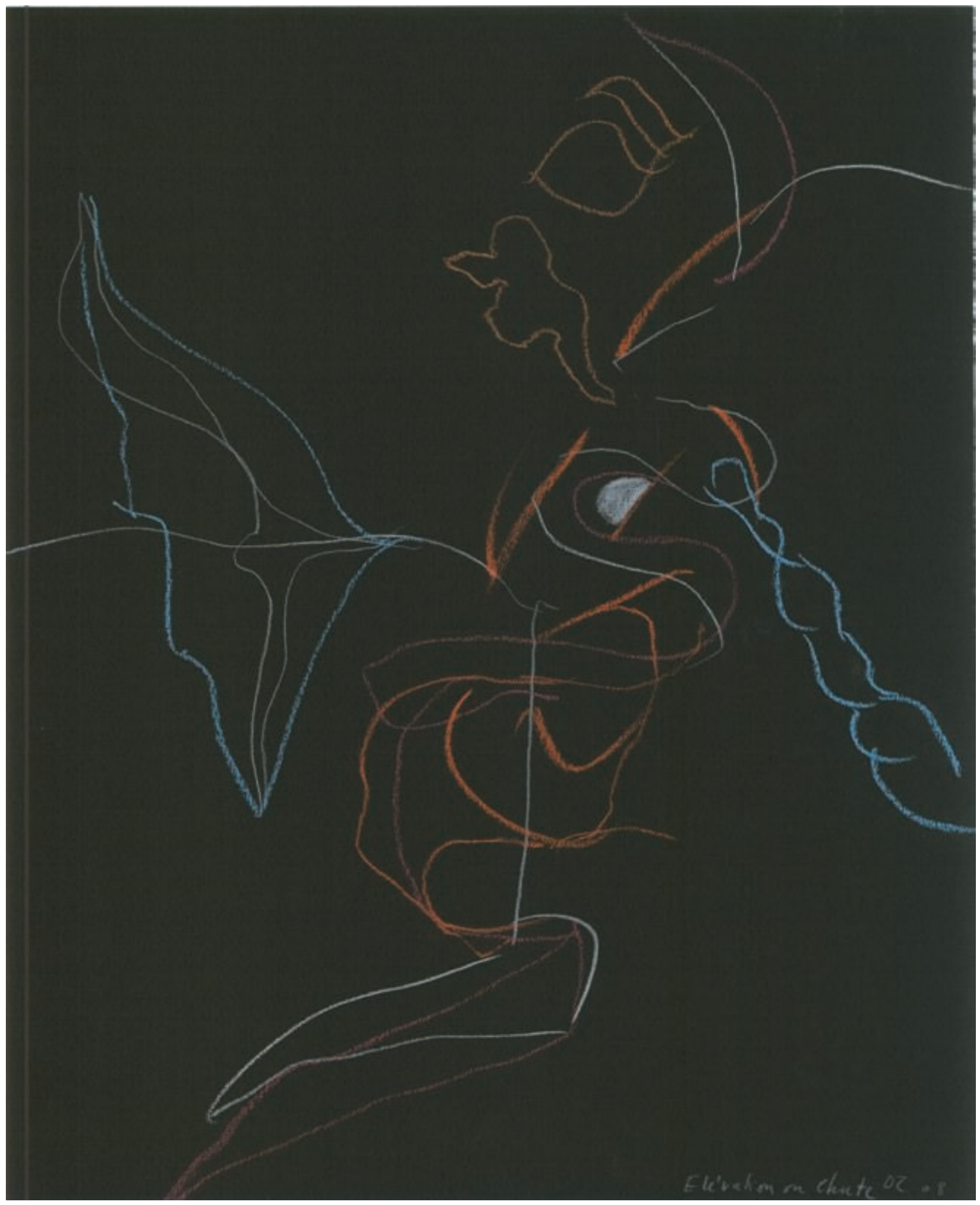





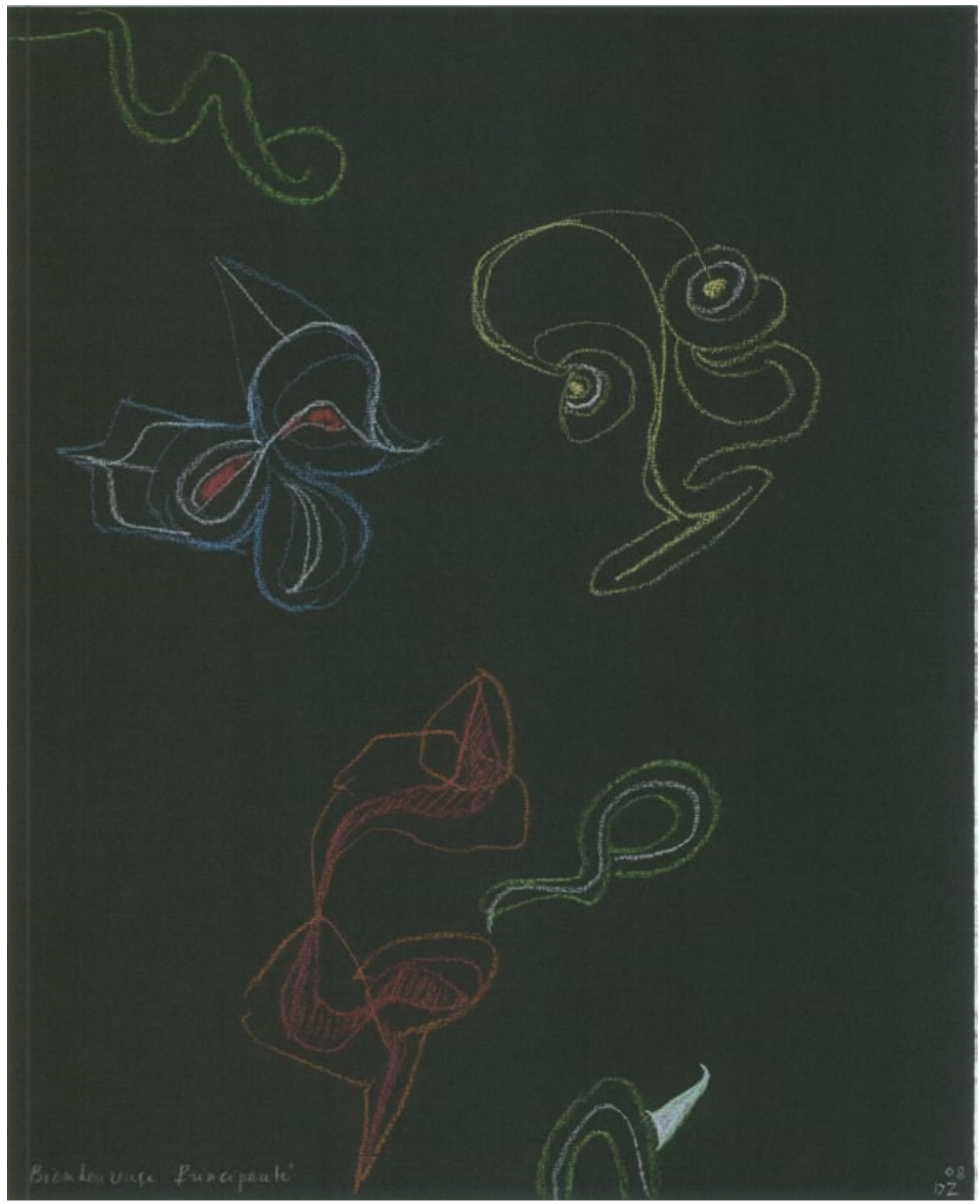




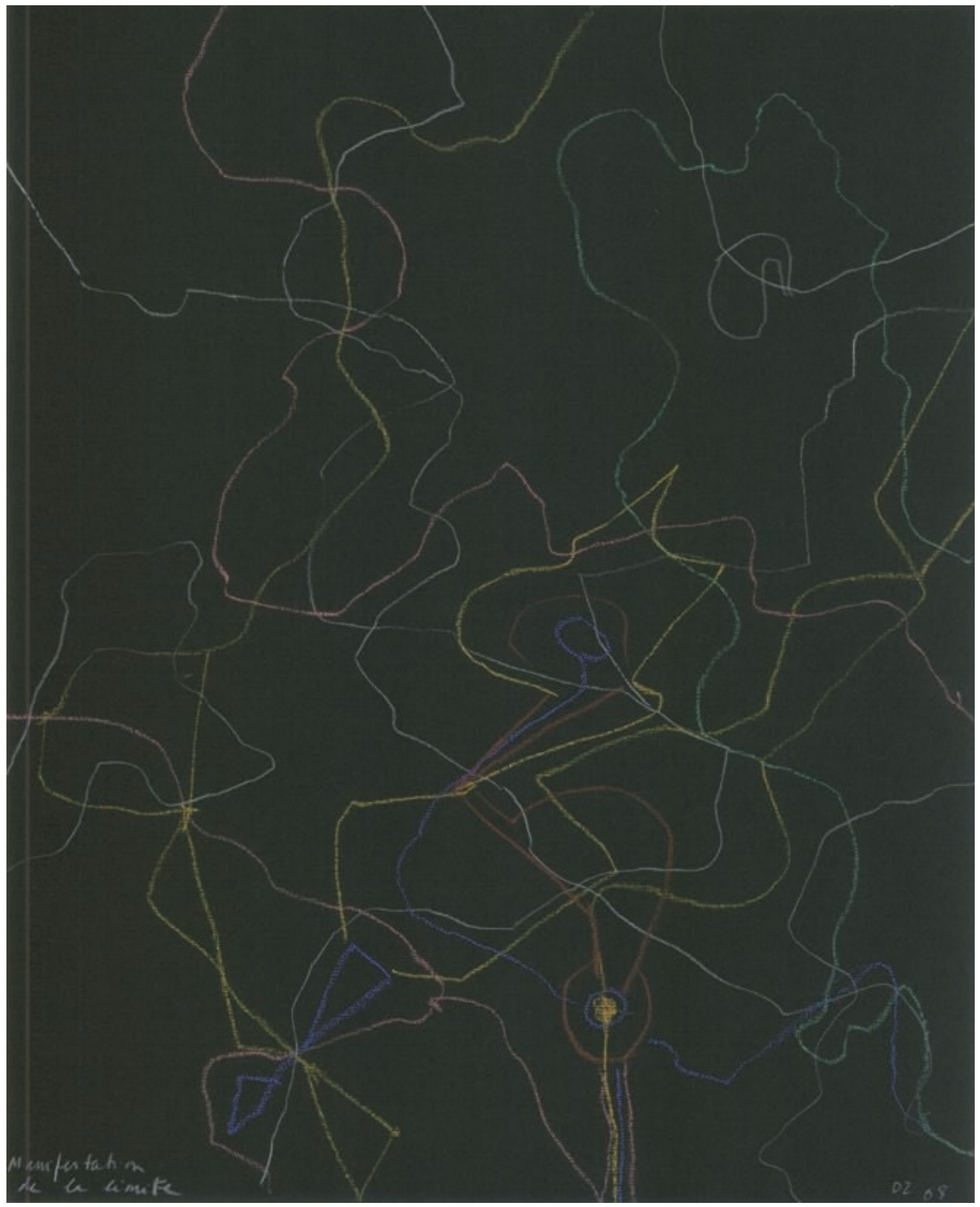




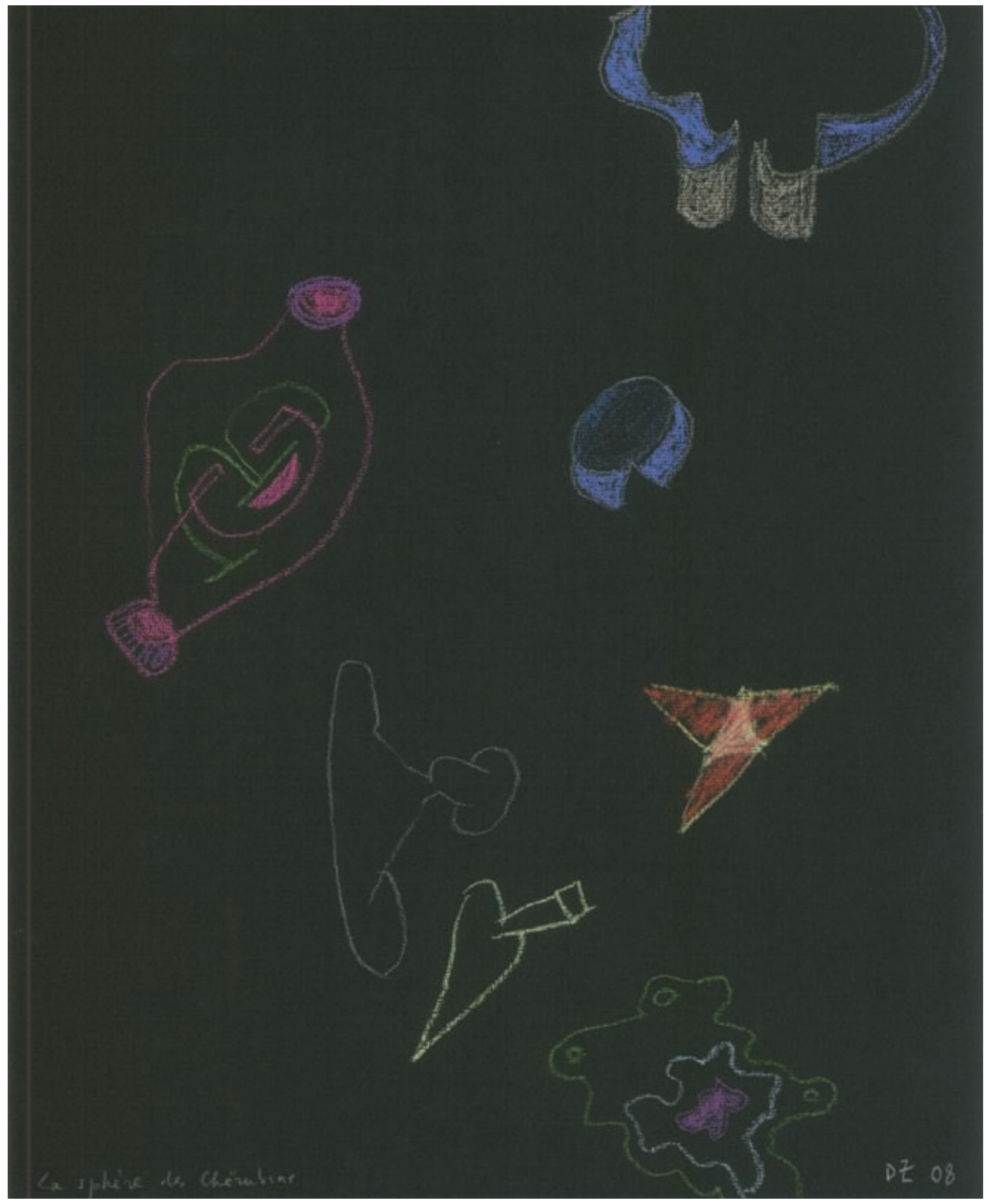




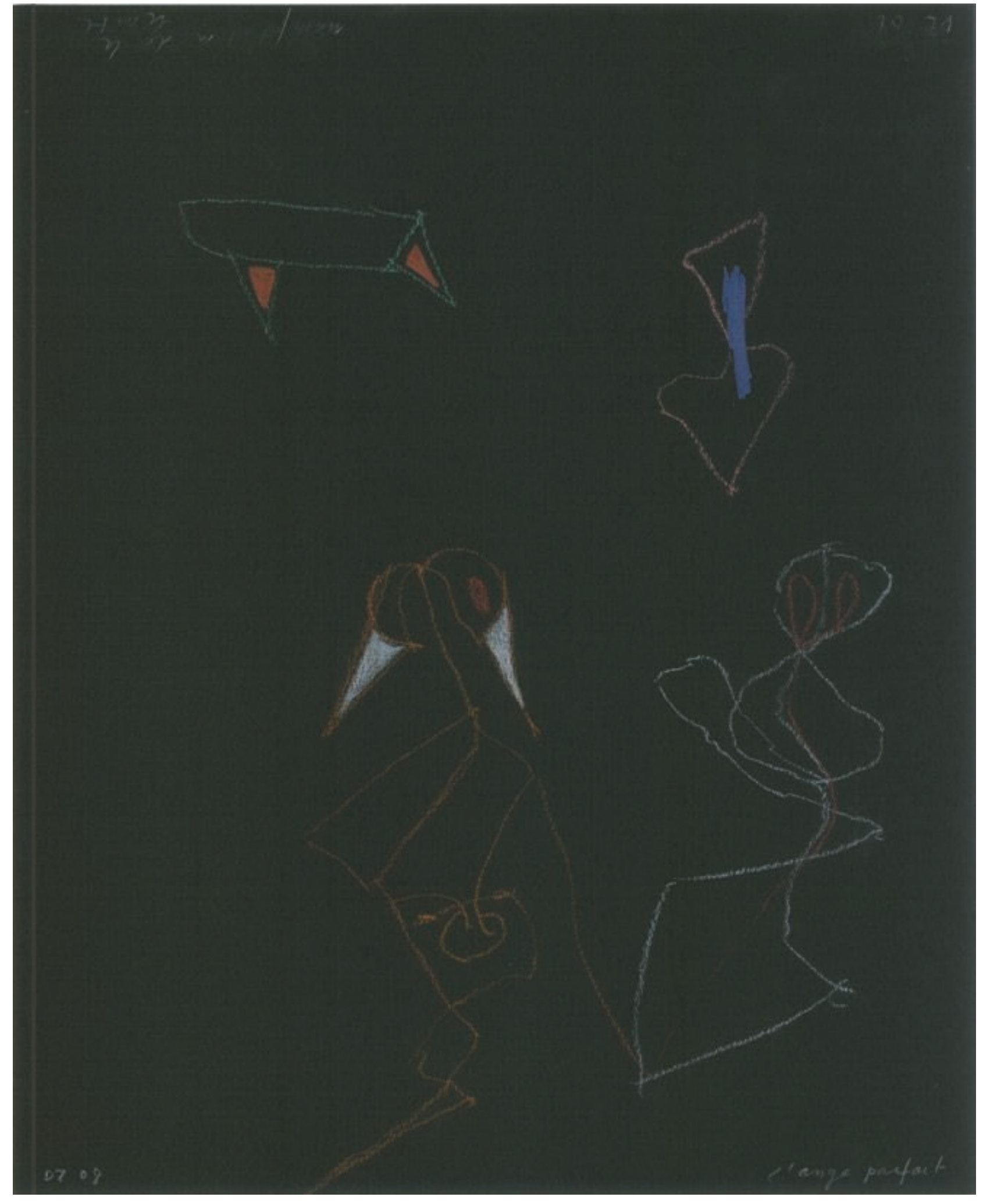




\section{Au sujet de mes dessins dits « gnostiques 》}

En revenant dans le Midi en 1978, je me suis intéressé fatalement au catharisme. Mais en remontant aux sources je suis tombé sur les courants gnostiques des premiers siècles de l'ère chrétienne.

En 1994, je publie La disquette de Tuchan avec mes propres illustrations, puis Vade-mecum pour gnostiques avancés en 2000, publié, avec mes dessins aussi, par les éditions Tarabuste.

Dans une note de 2002, j'écrivais :

"Les gnostiques font l'objet de toutes mes attentions dans la mesure où ils sont la pointe avancée des religions et une des origines de l'énorme bulle métaphysique occidentale, ainsi que les taoïstes chinois, autre pôle extrême de l'activité humaine (et de mon intérêt), qui sont des matérialistes radicaux. Entre ces deux pôles peuvent se tendre toutes les autres expériences de l'esprit (et du corps). C'est donc dans cette configuration 'stratégique' que je m'intéresse aux deux ".

(in Textes, entretiens, poèmes, éditions des Beaux-arts de Paris, p. 202)

Tout cela n'explique pas au lecteur l'inspiration gnostique des dessins que je présente ici. Je me contenterai de lui citer cette phrase de Christian Cannuyer dans Les chrétiens du Nil :

" La gnose (du grec 'gnosis', connaissance) consiste en effet pour l'homme à prendre conscience de la situation captive de son âme, pour l'en libérer et remonter vers la Lumière dont il est issu ".

\section{Daniel Dezeuze}

